\title{
Red blood cell count as an indicator of microvascular complications in Chinese patients with type 2 diabetes mellitus
}

This article was published in the following Dove Press journal:

Vascular Health and Risk Management

13 May 2013

Number of times this article has been viewed

\author{
Zhan-Sheng Wang ${ }^{1,2}$ \\ Zhan-Chun Song' \\ Jing-Hui Bai' \\ Fei $\mathrm{Li}^{3}$ \\ Tao $\mathrm{Wu}^{\prime}$ \\ Ji $\mathrm{Qi}^{2}$ \\ Jian $\mathrm{Hu}^{\prime}$
}

'Department of Cardiology, First Affiliated Hospital of China Medical University, ${ }^{2}$ Second Department of Cardiology, Fourth People's Hospital of Shenyang, Shenyang, ${ }^{3}$ Department of Cardiology, Shenzhou Hospital of Shenyang Medical College, Shenyang, People's Republic of China

Correspondence: Jian $\mathrm{Hu}$ Department of Cardiology, First Affiliated Hospital of China Medical University, Heping District, 155 North Nanjing St, Shenyang I I000I,

People's Republic of China

Tel +86248328 2739

Fax +86248328 2739

Email hujian9|3@medmail.com.cn
Background: Rheological disorders of red blood cells (RBC) and decreased RBC deformability have been involved in the development of diabetic microangiopathy. However, few studies have evaluated the association of RBC count with microvascular complications in patients with type 2 diabetes mellitus (T2DM). The purpose of this study was to investigate the association of RBC count with microvascular complications in patients with T2DM.

Methods: This study involved 369 patients with T2DM: 243 with one or more microvascular complications and 126 without microvascular complications. Anticoagulated blood was collected and analyzed in an automated blood cell counter. The presence of risk factors for microvascular complications was determined.

Results: The proportion of patients with microvascular complications increased as the RBC count decreased $(P<0.001)$. After adjustment for known risk factors for microvascular complications by logistic regression analysis, lower quartiles of RBC count were associated with a higher risk of microvascular complications compared with the reference group composed of the highest quartile (first quartile, odds ratio $4.98,95 \%$ confidence interval 1.54-6.19, $P=0.008$; second quartile, odds ratio $3.21,95 \%$ confidence interval $1.17-5.28, P=0.024$ ).

Conclusion: A decreased RBC count is associated with microvascular complications in Chinese patients with T2DM. The RBC count is a potential marker to improve further the ability to identify diabetic patients at high risk of microvascular complications.

Keywords: red blood cell count, microvascular complication, type 2 diabetes mellitus

\section{Introduction}

Diabetes is a complex and chronic metabolic disease characterized by hyperglycemia resulting from defects in the secretion and action of insulin. Type 2 diabetes mellitus (T2DM) is the most common form of diabetes, and is associated with the development of a number of devastating microvascular complications, including diabetic retinopathy (DR), diabetic peripheral neuropathy (DPN), and diabetic nephropathy (DN). ${ }^{1}$ Diabetes-induced microvascular complications are the major causes of morbidity and mortality in patients with T2DM. ${ }^{2}$ As these microvascular complications are important causes of morbidity, early diagnosis of the presence of such complications would help in reducing adverse cardiovascular events and associated health-care costs. ${ }^{3}$ Many conventional risk factors have been shown to be important contributors to the development of microvascular complications. ${ }^{4}$ Nevertheless, these risk factors cannot fully account for the excess risk produced by diabetes. ${ }^{5}$ Considerable effort has been expended in identifying patients at greater risk of microvascular complications, in particular because the traditional risk factors do not entirely explain 
the increased risk in diabetes. Multiple pathophysiological disorders have been involved in the development of diabetic microangiopathy, including rheological disorders of red blood cells (RBCs) and decreased RBC deformability. ${ }^{6,7}$ RBCs of patients with T2DM aggregate more readily than those of normal subjects. The abnormalities have been shown to markedly increase whole-blood viscosity, and the increased blood viscosity adversely affects the microcirculation in diabetes, leading to microangiopathy. ${ }^{8}$ In this study, we investigated the association of RBC count with microvascular complications in Chinese patients with T2DM.

\section{Materials and methods Study population}

The study population comprised 369 patients with T2DM attending the diabetic department of our hospital between January 2011 and July 2011. The patients we studied with different disease duration were mainly from northeast China and were mostly Han people, which is the largest ethnic group in the People's Republic of China. Patients with known hematologic diseases, such as hemolytic anemia, neoplastic metastases to marrow, pregnancy, severe arthritis, hypothyroidism, liver cirrhosis, posthemorrhagic anemia, renal anemia, inflammatory bowel diseases, and serious infection, in the past month that may have affected RBC count were excluded from the study.

Diagnosis of T2DM was established using World Health Organization 1999 criteria. The diagnostic criteria for DN, DPN, and DR were based upon the guidelines for T2DM treatment and prevention in the People's Republic of China (2010 edition). ${ }^{9}$ DR was defined by the presence of microaneurysms and/or retinal hemorrhage and/or neovascularization. DN was defined as microalbuminuria (30-300 mg/24 hours' urinary protein excretion) or macroalbuminuria (>300 mg/24 hours' urinary protein excretion). DPN was diagnosed based on clinical symptoms of allodynia/abnormal ankle reflex/ abnormal vibration sense or pressure sense abnormality. Data analyzed included age, sex, diabetes duration, smoking status, alcohol consumption, antihypertensive, antilipidemic, and antidiabetic medication, blood pressure, body mass index (BMI), fasting blood glucose, glycated hemoglobin $\left(\mathrm{HbA}_{1 \mathrm{c}}\right)$, lipid levels (including total cholesterol, high-density lipoprotein [HDL] cholesterol, triglycerides, and low-density lipoprotein [LDL] cholesterol), RBC count, hemoglobin, RBC distribution width (RDW), platelet count, and white blood cell (WBC) count. The study protocol was assessed and approved by the institutional ethics committee of the First Affiliated Hospital of China Medical University.

\section{Laboratory assays}

Blood samples were obtained from fasting patients. Two milliliters of venous blood was collected directly in an ethylenediaminetetraacetic acid vacutainer in sitting position from antecubital vein and analyzed after exactly 2 hours. Plasma glucose was measured by the hexokinase method (7600-100 automated analyzer; Hitachi, Tokyo, Japan). $\mathrm{HbA}_{1 \mathrm{c}}$ was measured using high-performance liquid chromatography (Variant II HbA 1c $_{\text {c }}$ HPLC System; BioRad Laboratories, Hercules, CA, USA). Total cholesterol (cholesterol oxidase method), triglycerides (removing free glycerol method), and HDL cholesterol (chemically modified enzyme method) were measured on the Hitachi 7600-110 automated analyzer using reagent kits supplied by Kyowa Medex (Tokyo, Japan). LDL cholesterol (selective melting method) was measured on the Hitachi 7600-110 automated analyzer using reagent kits supplied by Kyowa Medex. Urinary creatinine was measured by enzymatic methods on the Hitachi 7600-110 automated analyzer using reagent kits supplied by Kyowa Medex. Urinary albumin was measured by immunoturbidimetry on a BN II automated analyzer (Siemens, Munich, Germany) using reagent kits supplied by Kyowa Medex. A complete blood profile was determined using an automated cell counter (XE 2100; Sysmex, Kobe, Japan). The precision performance of these assays was within the manufacturers' specifications.

\section{Statistical analysis}

Data are presented as means \pm standard deviation for all normally distributed continuous variables, and median with interquartile ranges for non-normally distributed variables. One-way analysis of variance or Kruskal-Wallis tests were used as appropriate for between-group comparisons for continuous variables. Using data from clinical history, physical examination, and laboratory testing, Pearson's correlation coefficient was used in the context of normality to test univariate correlations with RBC count, and Spearman's correlation coefficient was used for correlation testing of non-normally distributed variables. Categorical variables were compared using the chi-squared test. Variables with a $P$-value $<0.10$ in univariate analysis were included in the multivariate model to identify predictors for the occurrence of diabetic microvascular complications. Predictors were removed from the model if their $P$-value exceeded 0.10 . RBC count was grouped into quartiles, and the adjusted odds ratio (OR) for each quartile was determined with the highest quartile as the reference group. The logistic regression model was used to estimate the OR and 95\% confidence interval (CI) 
for diabetic microvascular complications. In the regression analysis, known conventional risk factors for diabetic microvascular complications were included as covariates in the model. All tests were two-sided, and a $P$-value $<0.05$ was considered statistically significant. All data were analyzed by SPSS software (IBM, Armonk, NY, USA).

\section{Results}

The study population comprised 369 patients (204 male, 165 female; mean age $56.1 \pm 13.6$ years). Complete information about diabetic microvascular complications was available for all patients. The patients were stratified into four groups according to quartiles of RBC count, and the baseline characteristics of the groups are presented in Table 1. Clinical characteristics and laboratory findings of patients with or without microvascular complications are presented in Table 2. The proportion of patients with microvascular complications was $57.2 \%$ in male patients and $42.8 \%$ in female patients. The mean age of diabetic patients without complications was $50.1 \pm 14.2$ years, compared with $59.3 \pm 12.2$ years in the group with complications. The mean $\mathrm{RBC}$ count was $4.39 \pm 0.67 \times 10^{12} / \mathrm{L}$. Univariate analysis revealed that sex, smoking, alcohol consumption, age, duration of diabetes, BMI, systolic blood pressure, diastolic blood pressure, fasting plasma glucose, $\mathrm{HbA}_{1 \mathrm{c}}$, HDL cholesterol, triglycerides, WBC count, hemoglobin, RDW, and antihypertensive drugs were significantly different among the four groups $(P<0.05)$. Correlation analysis revealed positive associations of RBC count with BMI, diastolic blood pressure, fasting plasma glucose, $\mathrm{HbA}_{1 \mathrm{c}}$, triglycerides, WBC count, and hemoglobin, and negative associations with age, disease duration, systolic blood pressure, HDL cholesterol, and RDW $(P<0.05)$.

At baseline, the total proportion of patients with microvascular complications was $65.9 \%$. The proportions of DN and DR in patients with microvascular complications were $46.9 \%$ and $35.4 \%$, respectively. The proportion of patients with microvascular complications increased as the RBC count decreased $(P<0.001)$ (Figure 1).

Patients with lower RBC counts remained at increased risk of microvascular complications after adjustment for sex, age, smoking, duration of diabetes, BMI, systolic blood pressure, diastolic blood pressure, $\mathrm{HbA}_{1 \mathrm{c}}$, HDL cholesterol, triglycerides, WBC count, hemoglobin, RDW, and antihypertensive drugs $(P<0.001)$. Lower RBC quartiles were associated with a higher risk of microvascular complications

Table I Baseline clinical characteristics and laboratory findings of patients with type 2 diabetes mellitus by quartiles of red blood cell count $\left(\times 10^{12} / \mathrm{L}\right)$

\begin{tabular}{|c|c|c|c|c|c|}
\hline & $\begin{array}{l}\text { Ist quartile } \\
(1.4 \mid-4.07)\end{array}$ & $\begin{array}{l}\text { 2nd quartile } \\
(4.08-4.43)\end{array}$ & $\begin{array}{l}\text { 3rd quartile } \\
(4.44-4.83)\end{array}$ & $\begin{array}{l}\text { 4th quartile } \\
(4.84-6.44)\end{array}$ & $P$-value \\
\hline $\mathrm{n}$ & 92 & 92 & 92 & 93 & \\
\hline Male (\%) & $4 \mathrm{I}(44.6)$ & $32(34.8)$ & $53(57.6)$ & $78(55.3)$ & $<0.001$ \\
\hline Smokers (\%) & $23(25.0)$ & $12(13.0)$ & $27(29.3)$ & $40(43.1)$ & $<0.001$ \\
\hline Alcohol consumption (\%) & $14(20.0)$ & $12(13.0)$ & $23(25.0)$ & $29(31.2)$ & 0.007 \\
\hline Age (years) & $62.2 \pm 12.6$ & $59.3 \pm 12.4$ & $55.7 \pm 12.6$ & $47.5 \pm 12.4$ & $<0.001$ \\
\hline Disease duration (years) & $10.0(6.0-17.5)$ & $8.5(3.3-15.0)$ & $7.0(2.0-12.0)$ & $6.0(1.0-9.0)$ & $<0.001$ \\
\hline BMI $\left(\mathrm{kg} / \mathrm{m}^{2}\right)$ & $24.2 \pm 3.9$ & $25.5 \pm 4.1$ & $26.0 \pm 3.4$ & $26.6 \pm 3.8$ & 0.001 \\
\hline Systolic blood pressure (mmHg) & $140(130-160)$ & $130(\mid 20-140)$ & $130(120-140)$ & $130(120-140)$ & $<0.001$ \\
\hline Diastolic blood pressure $(\mathrm{mmHg})$ & $80(70-90)$ & $80(7 I-86)$ & $80(75-95)$ & $80(79-90)$ & 0.017 \\
\hline Fasting plasma glucose (mmol/L) & $6.41(5.30-9.75)$ & $8.09(6.48-10.94)$ & $8.39(6.90-11.54)$ & $9.58(7.36-12.52)$ & $<0.001$ \\
\hline $\mathrm{HbA}_{\text {Ic }}(\%)$ & $7.20(5.30-9.75)$ & $7.90(6.48-10.94)$ & $8.20(6.90-11.54)$ & $8.60(7.36-12.52)$ & $<0.001$ \\
\hline LDL cholesterol (mmol/L) & $2.72(2.17-3.59)$ & $3.26(2.50-3.78)$ & $2.92(2.43-3.64)$ & $2.96(2.38-3.59)$ & 0.276 \\
\hline HDL cholesterol (mmol/L) & $1.12(2.17-3.59)$ & $1.10(2.50-3.78)$ & $1.08(2.43-3.64)$ & $0.99(2.38-3.59)$ & 0.043 \\
\hline Total cholesterol (mmol/L) & $4.58(3.80-5.80)$ & $5.02(4.18-5.67)$ & $4.57(3.94-5.66)$ & $4.74(4.22-5.39)$ & 0.394 \\
\hline Triglycerides (mmol/L) & $1.24(0.93-1.84)$ & $1.62(1.01-2.40)$ & $1.60(1.13-2.70)$ & $1.98(1.26-3.13)$ & $<0.001$ \\
\hline WBC count $\left(10^{9} / \mathrm{L}\right)$ & $6.8(5.6-8.0)$ & $6.1(5.5-7.1)$ & $6.6(5.6-7.9)$ & $7.1(5.9-8.8)$ & 0.014 \\
\hline Hemoglobin $(\mathrm{g} / \mathrm{L})$ & III.5 (97.3-|| |9) & $128.5(125.0-135.0)$ & $139.0(\mid 35.0-145.0)$ & $153.0(147.0-159.0)$ & $<0.001$ \\
\hline RDW (\%) & $43(4 I-46)$ & $42(40-42)$ & $4 I(40-43)$ & $40(38-4 I)$ & $<0.001$ \\
\hline Platelets (10/L) & $224.4 \pm 76.8$ & $216.0 \pm 66.6$ & $218.5 \pm 57.1$ & $213.6 \pm 52.3$ & 0.700 \\
\hline Antihypertensive drug (\%) & $46(50.0)$ & $39(42.4)$ & $37(40.2)$ & $21(22.6)$ & 0.001 \\
\hline Antidyslipidemic drug (\%) & $4(4.3)$ & $\mathrm{I}(\mathrm{I} . \mathrm{I})$ & $3(3.3)$ & $2(2.2)$ & 0.558 \\
\hline Antidiabetic drug (\%) & $79(84.0)$ & $82(89.1)$ & 77 (83.7) & $73(78.5)$ & 0.277 \\
\hline
\end{tabular}

Abbreviations: $\mathrm{BMI}$, body mass index; $\mathrm{HbA}_{1 \mathrm{c}}$, glycated hemoglobin; LDL, low-density lipoprotein; HDL, high-density lipoprotein; WBC, white blood cell; RDW, red blood cell distribution width. 
Table 2 Clinical characteristics and laboratory findings of type 2 diabetes mellitus patients with or without microvascular complications

\begin{tabular}{|c|c|c|c|}
\hline & $\begin{array}{l}\text { Patients with microvascular } \\
\text { complications } \\
(n=243)\end{array}$ & $\begin{array}{l}\text { Patients without microvascular } \\
\text { complications } \\
(\mathrm{n}=126)\end{array}$ & $P$-value \\
\hline Male (\%) & $139(57.2)$ & $65(51.6)$ & 0.030 \\
\hline Smokers (\%) & $70(28.8)$ & $32(25.4)$ & 0.487 \\
\hline Alcohol consumption (\%) & $54(22.2)$ & $24(19.0)$ & 0.479 \\
\hline Age (years) & $59.3 \pm 12.2$ & $50.1 \pm 14.2$ & $<0.001$ \\
\hline Disease duration (years) & $10.0(5.0-14.5)$ & $4.0(1.0-10.0)$ & $<0.001$ \\
\hline $\mathrm{BMI}\left(\mathrm{kg} / \mathrm{m}^{2}\right)$ & $25.3 \pm 3.8$ & $26.2 \pm 4.0$ & 0.039 \\
\hline Systolic blood pressure $(\mathrm{mmHg})$ & $130(120-150)$ & $130(|20-| 40)$ & 0.001 \\
\hline Diastolic blood pressure $(\mathrm{mmHg})$ & $80(70-90)$ & $80(75-90)$ & 0.936 \\
\hline Fasting plasma glucose (mmol/L) & $8.19(6.4 \mid-11.08)$ & $8.66(6.61-11.56)$ & 0.351 \\
\hline $\mathrm{HbA}_{\mathrm{Ic}}(\%)$ & $8.10(6.80-9.20)$ & $8.10(6.90-9.50)$ & 0.368 \\
\hline LDL cholesterol (mmol/L) & $3.00(2.36-3.65)$ & $2.96(2.45-3.50)$ & 0.532 \\
\hline HDL cholesterol (mmol/L) & $1.09(0.90-1.32)$ & $\mathrm{I} .08(0.93-1.24)$ & 0.951 \\
\hline Total cholesterol (mmol/L) & $4.75(4.05-5.80)$ & $4.73(4.14-5.22)$ & 0.275 \\
\hline Triglycerides (mmol/L) & $1.59(1.04-2.48)$ & $1.60(1.04-2.57)$ & 0.707 \\
\hline WBC count $\left(10^{9} / \mathrm{L}\right)$ & $6.5(5.6-7.9)$ & $6.9(5.8-7.6)$ & 0.463 \\
\hline RBC count $\left(\times 10^{12} / L\right)$ & $4.32(3.97-4.69)$ & $4.59(4.33-4.97)$ & $<0.001$ \\
\hline Hemoglobin $(g / L)$ & $133(|19.0-| 44.0)$ & $139.0(\mid 29.0-152.0)$ & $<0.001$ \\
\hline RDW (\%) & $42(40-44)$ & $4 \mid(39-42)$ & $<0.001$ \\
\hline Platelets $\left(10^{9} / \mathrm{L}\right)$ & $216.2 \pm 65.2$ & $221.0 \pm 53.8$ & 0.326 \\
\hline Antihypertensive drug (\%) & $84(34.6)$ & $59(46.8)$ & 0.022 \\
\hline Antidyslipidemic drug (\%) & $7(2.9)$ & $3(2.4)$ & 0.779 \\
\hline Antidiabetic drug (\%) & $209(86.0)$ & $102(81.0)$ & 0.206 \\
\hline
\end{tabular}

Abbreviations: $n$, number; BMI, body mass index; $\mathrm{HbA}_{1 \mathrm{c}}$, glycated hemoglobin; LDL, low-density lipoprotein; HDL, high-density lipoprotein; WBC, white blood cell; RBC, red blood cell; RDW, red blood cell distribution width.

compared with the reference group (first quartile, OR 4.98, 95\% CI 1.54-6.19, $P=0.008$; second quartile, OR 3.21, 95\% CI 1.17-5.28, $P=0.024)$. Other independent predictors of microvascular complications in the study included age (OR $1.05,95 \%$ CI $1.02-1.07, P<0.001)$, duration of diabetes (OR 1.11, 95\% CI 1.07-1.16, $P<0.001)$, and $\mathrm{HbA}_{1 \mathrm{c}}(\mathrm{OR}$ $1.16,95 \%$ CI 1.04-1.29, $P=0.007)$. After RBC count was entered as a continuous variable into the model, the result did not change: $\mathrm{RBC}$ count remained significant. A 1-unit $\left(1 \times 10^{12} / \mathrm{L}\right)$ increase in $\mathrm{RBC}$ count was associated with a decreased risk of microvascular complications (OR 0.51, 95\% CI 0.28-0.93, $P=0.028$ ), DPN (OR 0.63, 95\% CI 0.43-0.91, $P=0.016)$, DN (OR 0.62, 95\% CI 0.40-0.94, $P=0.028)$, and DR (OR 0.57, 95\% CI 0.46-0.96, $P=0.003$ ).

\section{Discussion}

The principal finding of this study is that lower RBC counts, as reflected by $\mathrm{RBC}$ quartiles, are an independent predictor of the risk of microvascular complications in patients with T2DM, after controlling for conventional risk factors, including smoking, diabetes duration, BMI, blood pressure, lipids, and glucose.
Our data demonstrated that the risk of microvascular complications was 4.98-fold higher in patients with an RBC count $<4.07 \times 10^{12} / \mathrm{L}$ and 3.21-fold higher in patients with an $\mathrm{RBC}$ count $4.08-4.43 \times 10^{12} / \mathrm{L}$ than in those with an $\mathrm{RBC}$ count $>4.84 \times 10^{12} / \mathrm{L}$. The OR of microvascular complications increased in a stepwise manner with a decrease in quartile of RBC count.

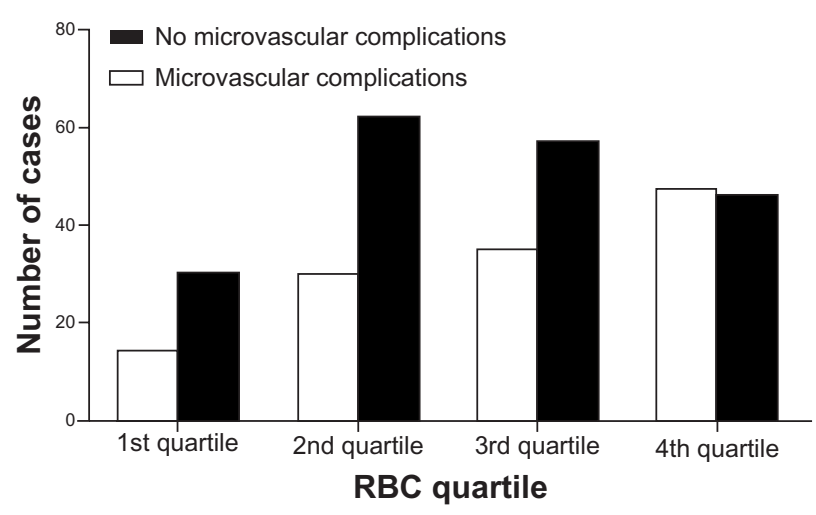

Figure I Percentage of the cases of type 2 diabetes mellitus with or without microvascular complications in patients within each quartile of red blood cell count. Note: $P<0.00$ I for trend.

Abbreviation: RBC, red blood cell. 
The hypothesis for the mechanism of the correlation between RBC count and microvascular complications might be that it is partly mediated through an effect of decreased RBC count on RBC function. There have been a few studies to support this notion in patients with DM in the available literature. First, structural alterations of the $\mathrm{RBC}$ membrane proteins are associated with the development of microvascular complications in diabetes. ${ }^{10} \mathrm{Chronic}$ hyperglycemia causes nonenzymatic glycosylation of RBC membrane proteins, which reduces the negative surface electric charge, leading to accelerated aging of RBCs. ${ }^{11-13}$ The decreased $\mathrm{RBC}$ count can further reduce the negative charge of RBCs. Sialic acid moieties of RBC membrane glycoproteins are the principal determinants of the negative charge on the cell surface. The decreased cell surface charge is thought to firm adhesion between surfaces. ${ }^{14}$ The resultant electrostatic repulsion between the cells diminishes RBC aggregation, resulting in low shear-rate viscosity and yield stress of blood..$^{15,16}$ Therefore, a decrease in the negative charge of RBCs may increase microviscosity, aggregation, and adhesiveness of RBCs. The decrease of surface charge leads to a collinear decrease of membrane deformability. ${ }^{17}$ $\mathrm{RBC}$ velocity becomes intermittent and/or RBCs come to a complete standstill when RBCs entering and moving through capillary segments are decreased by a reduction in the net surface charge of RBCs. ${ }^{18}$ Older RBCs demonstrate increased mechanical fragility, decreased deformability, and increased ability to aggregate compared with younger RBCs. ${ }^{19}$ Some hemoglobin molecules of aging RBCs are aggregated and attach to the inside of the cell membrane. ${ }^{17}$ The binding of hemoglobin to the inside of the cell membrane can lead to a reduction in membrane flexibility and influence the oxygenation of hemoglobin..$^{20} \mathrm{~A}$ low RBC negative charge in patients with T2DM is also associated with DR and changes in the properties of the retinal basement membrane. ${ }^{21}$ These changes cause breakdown of the bloodretinal barrier, which results in capillary hyperpermeability and leakage of proteins into the deep and superficial layers of the retina. ${ }^{22}$ In normal mammalian cells, phosphatidylserine, which contains a negative charge, is exclusively confined to the inner layer of the plasma membrane. ${ }^{23,24}$ Increased intracellular oxidative stress can impair maintenance of phospholipid asymmetry, resulting in phosphatidylserine externalization. ${ }^{25}$ Loss of this asymmetric distribution and exposure of phosphatidylserine on the external surface generate a thrombogenic surface and signal macrophages to remove cells by phagocytosis. ${ }^{26}$ An enhancement of blood coagulation was also observed in the presence of erythrocytes, leukocytes, and phosphatidylserine. ${ }^{27}$

Second, reduced hemoglobin levels independently identify diabetic patients with an increased risk of microvascular complications. ${ }^{28,29}$ Anemia causes tissue hypoxia that has a multitude of fibrogenic and mitogenic effects in an already-compromised kidney via expression of multiple growth factors, hormones, vasoactive reagents, and enzymes. ${ }^{30,31}$ Hypoxia can also contribute to renal vasoconstriction by stimulating the sympathetic nervous system and resultant activation of the intrarenal reninangiotensin system. ${ }^{32}$ The renal vasoconstriction may initiate nephropathy. In this study, the RBC count showed a positive correlation with the serum hemoglobin level. The decrease in RBC count in diabetics may contribute to the occurrence of microvascular complications mediated by a decreased hemoglobin level.

Third, erythropoietin deficiency results in normochromic normocytic anemia that occurs early in $\mathrm{DN}$, often prior to the decline in renal function. ${ }^{33}$ Therefore, the RBC count in normochromic normocytic anemia may provide some indication of damage to the cells and vascular architecture of the renal tubulointerstitium associated with DN that may be apparent before demonstrable changes in renal function. ${ }^{34}$ Anemia in early $\mathrm{DN}$ is also induced by a poor response of erythropoietin to low hemoglobin levels as a result of impaired sensing mechanisms associated with autonomic DN. ${ }^{35}$

In addition, higher values of RDW reflect greater variation in the distribution of RBC volumes. Higher RDW values are associated with increased risk for cardiovascular disease and nephropathy in adult patients with diabetes. ${ }^{36,37}$ Increased RDW was associated with decreased RBC deformability, which can impair blood flow through the microcirculation. ${ }^{38}$ RBC deformability plays a role, as elevated RDW is associated with increased inflammation and decreased levels of antioxidants. ${ }^{39}$ Moreover RDW is elevated in conditions of ineffective red cell production (eg, iron deficiency, anemia of chronic disease, $\mathrm{B}_{12}$ or folate deficiency) and increased red cell destruction (eg, hemolysis). ${ }^{40}$

These results suggest that $\mathrm{RBC}$ count is a potential candidate to improve further our ability to identify patients at high risk of developing microvascular complications and institute appropriate preventive measures. The work described here may motivate further studies in comparisons of RBC concentration and microcirculation using Doppler perfusion imaging or laser speckle perfusion imaging for the investigation of tissue microcirculation. ${ }^{41}$ The present findings are limited in 
their ability to eliminate causal relationships between RBC count and microvascular complications in T2DM. Further prospective population-based studies are needed to investigate the mechanisms in order to answer these questions.

In conclusion, a decreased RBC count is associated with microvascular complications in Chinese patients with T2DM. It indicated that lower RBC counts may be related to RBC membrane protein alterations, a decrease in hemoglobin levels, and erythropoietin deficiency.

\section{Disclosure}

The authors report no conflicts of interest in this work.

\section{References}

1. Hinnen D. The role of the kidney in hyperglycemia: a new therapeutic target in type 2 diabetes mellitus. J Cardiovasc Nurs. 2013;28(2): $157-165$.

2. Choi SK, Galán M, Kassan M, Partyka M, Trebak M, Matrougui K. Poly(ADP-ribose) polymerase 1 inhibition improves coronary arteriole function in type 2 diabetes mellitus. Hypertension. 2012;59(5): 1060-1068.

3. Jindal S, Gupta S, Gupta R, et al. Platelet indices in diabetes mellitus: indicators of diabetic microvascular complications. Hematology. 2011; 16(2):86-89.

4. Tong PC, Lee KF, So WY, et al. White blood cell count is associated with macro- and microvascular complications in Chinese patients with type 2 diabetes. Diabetes Care. 2004;27(1):216-222.

5. Stamler J, Vaccaro O, Neaton JD, Wentworth D. Diabetes, other risk factors, and 12-yr cardiovascular mortality for men screened in the Multiple Risk Factor Intervention Trial. Diabetes Care. 1993;16(2): 434-444.

6. Hoare EM, Barnes AJ, Dormandy JA. Abnormal blood viscosity in diabetes mellitus and retinopathy. Biorheology. 1976;13(1):21-25.

7. Schwartz RS, Madsen JW, Rybicki AC, Nagel RL. Oxidation of spectrin and deformability defects in diabetic erythrocytes. Diabetes. 1991;40(6):701-708.

8. Cho YI, Mooney MP, Cho DJ. Hemorheological disorders in diabetes mellitus. J Diabetes Sci Technol. 2008;2(6):1130-1138.

9. Association CD. Guideline for the diagnosis and treatment of type 2 diabetes in China (2010 edition). Chin J Diabetes. 2012;20(1):S1-S36.

10. Petropoulos IK, Margetis PI, Antonelou MH, et al. Structural alterations of the erythrocyte membrane proteins in diabetic retinopathy. Graefes Arch Clin Exp Ophthalmol. 2007;245(8):1179-1188.

11. Miller JA, Gravallese E, Bunn HF. Nonenzymatic glycosylation of erythrocyte membrane proteins. Relevance to diabetes. J Clin Invest. 1980;65(4):896-901.

12. Baba Y, Kai M, Setoyama S, Otsuji S. The lower levels of erythrocyte surface electric charge in diabetes mellitus. Clin Chim Acta. 1978; 84(1-2):247-249.

13. Mazzanti L, Faloia E, Rabini RA, et al. Diabetes mellitus induces red blood cell plasma membrane alterations possibly affecting the aging process. Clin Biochem. 1992;25(1):41-46.

14. Mege JL, Capo C, Benoliel AM, Bongrand P. Use of cell contour analysis to evaluate the affinity between macrophages and glutaraldehyde-treated erythrocytes. Biophys J. 1987;52(2):177-186.

15. Rogers ME, Williams DT, Niththyananthan R, Rampling MW, Heslop KE, Johnston DG. Decrease in erythrocyte glycophorin sialic acid content is associated with increased erythrocyte aggregation in human diabetes. Clin Sci (Lond). 1992;82(3):309-313.

16. McMillan DE, Utterback NG, Wujek JJ. Effect of anionic amphophiles on erythrocyte properties. Ann NY Acad Sci. 1983;416:633-641.
17. Huang YX, Wu ZJ, Mehrishi J, et al. Human red blood cell aging: correlative changes in surface charge and cell properties. J Cell Mol Med. 2011;15(12):2634-2642.

18. Vink H, Wieringa PA, Spaan JA. Evidence that cell surface charge reduction modifes capillary red cell velocity-flux relationships in hamster cremaster muscle. J Physiol. 1995;489(Pt 1):193-201.

19. Kameneva MV, Antaki JF, Borovetz HS, et al. Mechanisms of red blood cell trauma in assisted circulation. Rheologic similarities of red blood cell transformations due to natural aging and mechanical stress. ASAIO J. 1995;41(3):M457-M460.

20. Ideguchi $\mathrm{H}$. Effects of abnormal $\mathrm{Hb}$ on red cell membranes. Rinsho Byori. 1999;47(3):232-237. Japanese.

21. Budak Y, Demirci H, Akdogan M, Yavuz D. Erytrocyte membrane anionic charge in type 2 diabetic patients with retinopathy. $B M C$ Ophthalmol. 2004;4:14.

22. D'Amico DJ. Diseases of the retina. N Engl J Med. 1994;331(2): 95-106.

23. Zwaal RF, Schroit AJ. Pathophysiologic implications of membrane phospholipid asymmetry in blood cells. Blood. 1997;89(4):1121-1132.

24. Kimelberg HK. Differential distribution of liposome-entrapped [3H] methotrexate and labelled lipids after intravenous injection in a primate. Biochim Biophys Acta. 1976;448(4):531-550.

25. Kanno H. Critical role of phosphatidylserine in hemolysis due to red blood cell enzyme/membrane defects. Nihon Rinsho. 2008;66(3): 461-468. Japanese.

26. Neidlinger NA, Larkin SK, Bhagat A, Victorino GP, Kuypers FA. Hydrolysis of phosphatidylserine-exposing red blood cells by secretory phospholipase A2 generates lysophosphatidic acid and results in vascular dysfunction. J Biol Chem. 2006;281(2):775-781.

27. Miyamoto M, Sasakawa S, Ozawa T, Kawaguchi H, Ohtsuka Y. Mechanisms of blood coagulation induced by latex particles and the roles of blood cells. Biomaterials. 1990;11(6):385-388.

28. Keane WF, Brenner BM, de Zeeuw D, et al. The risk of developing end-stage renal disease in patients with type 2 diabetes and nephropathy: the RENAAL study. Kidney Int. 2003;63(4):1499-1507.

29. Thomas MC. Anemia in diabetes: marker or mediator of microvascular disease? Nat Clin Pract Nephrol. 2007;3(1):20-30.

30. Deicher R, Hörl WH. Anaemia as a risk factor for the progression of chronic kidney disease. Curr Opin Nephrol Hypertens. 2003;12(2): 139-143.

31. Fine LG, Bandyopadhay D, Norman JT. Is there a common mechanism for the progression of different types of renal diseases other than proteinuria? Towards the unifying theme of chronic hypoxia. Kidney Int Suppl. 2000;75:S22-S26.

32. Grunwald JE, Riva CE, Sinclair SH, Brucker AJ, Petrig BL. Laser Doppler velocimetry study of retinal circulation in diabetes mellitus. Arch Ophthalmol. 1986;104(7):991-996.

33. Kim MK, Baek KH, Lim DJ, et al. Erythropoietin response to anemia and its association with autonomic neuropathy in type 2 diabetic patients without advanced renal failure. J Diabetes Complications. 2010;24(2):90-95.

34. Thomas M, Tsalamandris C, MacIsaac R, Jerums G. Anaemia in diabetes: an emerging complication of microvascular disease. Curr Diabetes Rev. 2005;1(1):107-126.

35. McGill JB, Bell DS. Anemia and the role of erythropoietin in diabetes. J Diabetes Complications. 2006;20(4):262-272.

36. Tonelli M, Sacks F, Arnold M, et al. Relation between red blood cell distribution width and cardiovascular event rate in people with coronary disease. Circulation. 2008;117(2):163-168.

37. Malandrino N, Wu WC, Taveira TH, Whitlatch HB, Smith RJ. Association between red blood cell distribution width and macrovascular and microvascular complications in diabetes. Diabetologia. 2012; 55(1):226-235.

38. Patel KV, Mohanty JG, Kanapuru B, Hesdorffer C, Ershler WB, Rifkind JM. Association of the red cell distribution width with red blood cell deformability. Adv Exp Medicine Biol. 2013;765: 211-216. 
39. Semba RD, Patel KV, Ferrucci L, et al. Serum antioxidants and inflammation predict red cell distribution width in older women: the Women's Health and Aging Study I. Clin Nutr. 2010;29(5):600-604.

40. Allen LA, Felker GM, Mehra MR, et al. Validation and potential mechanisms of red cell distribution width as a prognostic marker in heart failure. J Card Fail. 2010;16(3):230-238.
41. O’Doherty J, McNamara P, Clancy NT, Enfield JG, Leahy MJ. Comparison of instruments for investigation of microcirculatory blood flow and red blood cell concentration. J Biomedical Opt. 2009;14(3): 034025 .

\section{Publish your work in this journal}

Vascular Health and Risk Management is an international, peerreviewed journal of therapeutics and risk management, focusing on concise rapid reporting of clinical studies on the processes involved in the maintenance of vascular health; the monitoring, prevention and treatment of vascular disease and its sequelae; and the involvement of metabolic disorders, particularly diabetes. This journal is indexed on PubMed Central and MedLine. The manuscript management system is completely online and includes a very quick and fair peer-review system, which is all easy to use. Visit http://www.dovepress.com/ testimonials.php to read real quotes from published authors.

Submit your manuscript here: http://www.dovepress.com/vascular-health-and-risk-management-journal 